\title{
Enhancing the quality of teaching and learning in Tanzania through improved English language teaching and educational management skills
}

\author{
Mkonongwa, Luka Mathayo \\ Dar es Salaam University College of Education, Tanzania (mkonongwa@gmail.com) \\ Komba, Sotco Claudius $\square$ \\ Sokoine University of Agriculture, Tanzania (sotratz@suanet.ac.tz)
}

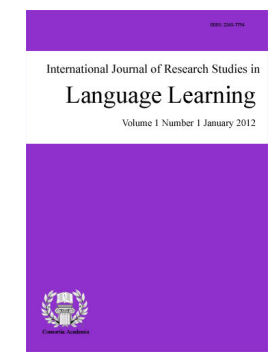

ISSN: 2243-7754 Online ISSN: 2243-7762

OPEN ACCESS

Received: 7 December 2016

Revised: 21 March 2017

Available Online: 12 April 2017

DOI: $10.5861 /$ ijrsll.2017.1705

Accepted: 27 March 2017

\section{Abstract}

In 2012, the British Council and the Government of Tanzania through the then Ministry of Education and Vocational Training, now Ministry of Education, Science and Technology, implemented a four-year project, known as Education Development and Quality Improvement Project for English Language Teacher Training in Tanzania (EQUIP T-ELT). The purpose of the project was to improve the quality of teaching and learning in teachers' colleges, secondary and primary schools, with a specific focus on English as a language of instruction and communication. The project implementation ended in March 2016. Therefore, this study was conducted to examine the impact of the project on both institutions and staff. A total of 207 participants were involved in the study, including college principals, 181 tutors, 12 district teacher trainers and 10 material developers. The study employed mixed methods research design, in which both qualitative and quantitative methods were used during the data collection, analysis and presentation. Specifically, the data were collected through survey questionnaires, interview schedules, focus group discussions and document desk reviews. Data were analyzed using Statistical Package for Social Sciences (SPSS) and ATLAS.ti. 6.2. The findings indicated that the provision of two complementary interventions, English language improvement and improvement in pedagogy and educational management skills, had a significant impact on the participants as they were able to use the knowledge and skills from the two interventions simultaneously in their day to day teaching and institutional management. Moreover, the findings revealed that there were vital professional changes at both institutional and individual levels which emanated from the interventions. The changes include improved human resource capacity, improved English language proficiency, and improved pedagogical and leadership skills. It was also found that the project enabled tutors to share knowledge and skills acquired from the two interventions with their colleagues, hence developing a sense of team work in teaching as well as in accomplishing college administrative activities. Based on these findings, it is recommended that the Ministry of 
Mkonongwa, L. M., \& Komba, S. C.

Education, Science and Technology, should encourage the tutors, who had their knowledge and skills improved through their involvement in the EQUIPT-ELT project, to share their knowledge and skills with their colleagues who were not involved in the project, in order to have an everlasting impact of the project.

Keywords: education development; English language improvement; teaching and learning; teacher training; Tanzania 


\section{Enhancing the quality of teaching and learning in Tanzania through improved English language teaching and educational management skills}

\section{Introduction}

The Government of Tanzania is striving to provide high quality education to all Tanzanians. Different strategies and policies have been developed by the government to respond to the increasing demand for education by Tanzanians. Since the government of Tanzania acknowledges the importance of education in human and national development, it emphasizes on investing in education through all of its development plans and strategies. Examples of the national strategies and plans that emphasize on the investment in education include the National Strategy for Growth and Reduction of Poverty (NSGRP/MKUKUTA II), the Five Year Development Plan (5YDP), and Big Results Now Initiative which embraces Education for All (EFA) goals. Others include the Tanzania Development Vision 2025, Primary Education Development Programme (PEDP), and Secondary Education Development Programme (SEDP).

Although Tanzania has a wide range of policies, strategies and plans which focus on education, disparities in education provision are increasing. For example, the net primary enrolment rate reached its pick in 2007, and thereafter, started falling (United Republic of Tanzania, 2010). Likewise, performance rate in the Certification of Secondary Education Examination has been decreasing steadily since 2012, whereas the transition rate from primary to secondary education has remained at 55\%, with high regional disparities ranging between $30 \%$ and 55\% (United Republic of Tanzania, 2014). Moreover, the ability of secondary education graduates to express themselves in English has been declining with some of the graduates being unable to write a simple sentence in English. The poorly learned graduates at Form Four level are being recycled into the education system, in which some of the graduates who cannot express themselves clearly in English become teachers in primary and secondary schools and teacher training colleges. This has adversely affected the quality of education provided by both schools and colleges. Considering that the language of instruction at secondary education level is English, students are forced to learn in a language which they have not mastered.

\section{English language in Education}

In Tanzania, English language is used as a medium of instruction from secondary education to higher education. With an exception of private English-medium schools and only eleven public primary schools where English is used as a medium of instruction, the rest of primary schools in the country teach English as a subject. This approach of English language use in Tanzanian schools has caused a serious problem to students when transiting from primary to secondary education where they experience a sharp shift from Swahili to English. The change of the language of instruction has often created a learning gap because students face difficulties in communicating by using the language of instruction, consequently failing to cope well with secondary curriculum (Komba \& Bosco, 2015; Murasi, 2013; Sumra \& Rajani, 2006; Mwinsheikhe, 2003). For example, Sumra and Rajan (2006) report that the majorities of public primary school leavers develop little confidence in English and cannot write a simple paragraph. Consequently, they are unable to follow what is taught or written in English in secondary school and this contributes to poor learning.

Studies have also revealed that the poor performance in the final secondary examinations is highly contributed by the language barrier (Mosha, 2014; Brock-Utne et al., 2010). Such language problems have a cyclic effect because school leavers with poor language skills and competences ultimately join tertiary education, including teacher training colleges and universities, in which the language deficiencies are carried over. This is clearly noted by Galabawa and Senkoro (2010) who point out that the problem of English language is not confined to the primary and secondary schools alone, but there is lack of the ability of lecturer and students at the university level in Tanzania to communicate effectively in English. This implies that teachers graduate with poor 
English language mastery and in return they are posted to schools where they use it as a language of instructionexacerbating the problem. Concurrently, research by Makewa (2013) and Mlay (2010) has shown that many teachers in Tanzania lack the ability to communicate effectively in English, and consequently affecting the quality of the graduates from both secondary and higher learning institutions.

In 2012, the Government of Tanzania through the then Ministry of Education and Vocational Training, now Ministry of Education, Science and Technology, in collaboration with the British Council, launched a four-year project titled, Education Development and Quality Improvement Project for English Language Teacher Training in Tanzania (EQUIP T-ELT), as an intervention to address the problem of English language in teachers' colleges, secondary and primary schools. The purpose of the project was to improve the quality of teaching and learning in teachers' colleges, secondary and primary schools with a specific focus on English as a language of instruction and communication. It was envisaged that if teachers' English language skills were improved, the teachers would teach confidently using English as the medium of instruction. In addition, the project sought to provide a framework for college management teams to support tutors' professional development and their role to support student teachers. Specifically, the project sought to achieve three main outcomes as follows: First, having strengthened capacity to deliver effective programmes to support teaching through the medium of English; secondly, having improved capacity in teacher training colleges to deliver quality teaching and, lastly, having increased awareness of policy and practice on teaching through the medium of English.

The project was funded by UKAID and started in November 2012 and ended in March 2016. Initially, the project was implemented in all 34 government teacher training colleges in mainland Tanzania, but in 2014, the project objectives were revised. As a result, from June 2014 the focus was changed to addressing staff in 16 Diploma Teachers' Colleges and 3 Certificate Teachers' Colleges. The project was conducted in two phases. The first phase focused on the training of tutors and college management staff while the second phase focused on material development and development of a national training team of tutors to train teacher trainers and secondary school teachers.

The implementation of the project involved two organizations, namely the British Council (BC) and the Volunteer Service Overseas (VSOs), which coordinated two separate interventions. The British Council dealt with English language training and the VSOs provided training, mentoring and coaching on pedagogy and management skills. Both interventions adopted a College-based training model although they used different approaches to deliver their training activities. It was envisaged that the two interventions would complement each other in terms of knowledge, skills and competences offered to the trainees. It is worth noting that in the first phase of the intervention, the main activity was training which focused on two major areas: improving English for use as language of instruction in the colleges and developing tutors in pedagogical and leadership skills. The British Council used a course - English for Teaching (EfT) - as a framework for their activity while the VSOs supported tutors with pedagogical and leadership skills. As noted earlier, the activities of the two interventions were expected to complement each other.

The British Council used English language experts from different countries in the world, including America, Asia, Europe and Africa. The VSO team comprised professional volunteers in pedagogy and leadership whose primary role was to empower tutors and teachers to coach each other. As indicated in Table 1, the two teams largely worked autonomously and they used different approaches to deliver their programmes. The British Council used college-based trainers who were individually full-time placed in the colleges and conducted their training daily in the form of normal classroom sessions. In contrast, the VSO facilitators worked in a team of three facilitators who conducted their training in the form of workshops and seminars, organized on rotational basis across the colleges. In general, the two interventions were designed in such a way that the skills acquired from the two interventions were expected to be applied with student teachers who would be following the same English language course the tutors had followed.

In the course of implementation, the project employed various models of in-service training and 
Enhancing teaching and learning through improved English language teaching and educational management development. The intervention approaches adopted are indicated in Table 1. The project was originally designed in such a way that Approach 1 and Approach 2 interventions in the first phase would complement each other and reinforce the shift towards Approach 3 and 4 within Teachers' Colleges in the second phase of the project.

Table 1

Approaches adopted in implementing the interventions

\begin{tabular}{|c|c|c|}
\hline Approach & Area(s) of interest & Delivered by \\
\hline 'Implants' & $\begin{array}{l}\text { English language proficiency development, } \\
\text { methodology, mentoring }\end{array}$ & College-based trainers $(\mathrm{BC})$ \\
\hline Team visits & $\begin{array}{l}\text { Pedagogy and methodology training, leadership, } \\
\text { performance review }\end{array}$ & VSO facilitators \\
\hline Intensive 'hub' training & $\begin{array}{l}\text { Baseline induction (core team), materials } \\
\text { development }\end{array}$ & Consultants/trainers \\
\hline Mentoring/peer training & Baseline cascade training, student teacher training & $\begin{array}{l}\text { Trainers, VSO quality } \\
\text { facilitators }\end{array}$ \\
\hline
\end{tabular}

This paper emanates from a study which was conducted to examine the impact of the project on both institutions and staff who were involved in the project. Specifically, the study sought to achieve the following objectives:

$>$ To examine the effects of providing two complementary interventions (i.e. English language improvement and improvement in pedagogy and educational management skills) in Phase 1

$>\quad$ To examine the shorter and longer-term effects of using a college-based intervention model

$>\quad$ To examine the professional development changes individual tutors and the colleges had undergone as a result of the interventions.

$>\quad$ To find out whether there was any perceived relationship between Year 1 and Year 2 intervention activities and subsequent professional development for Baseline training group and the materials development group.

$>$ To examine if there was any cross-over effect of skills from the Baseline core team members to their college departments.

\section{Methodology}

Initially, the project was implemented in 34 colleges. However, from June 2014, the focus was changed to addressing staff in 16 Diploma teachers' colleges and 3 Certificate teachers' colleges, making a total of 19 colleges. In this study, only eight teachers' colleges, including five diploma colleges and three certificate colleges, were involved. The inclusion criterion was that of a college having staff who were involved in one way or the other in implementing the project. Stratified sampling technique was used to select the eight colleges from four education zones in Tanzania namely East Zone, Lake Zone, Southern Highlands Zone and North East Zone. The selected colleges included Mpuguso (Mbeya), Klerruu (Iringa), Morogoro (Morogoro), Vikindu (Coast), Marangu (Kilimanjaro), Patandi (Arusha), Butimba (Mwanza) and Katoke (Kagera). The participants in this study were tutors and principals of the colleges. The tutors were divided into three categories: those who served as national trainer of trainers, those who were involved in material development (Baseline core-team) and those who attended English language training, conducted by the British Council Trainers (BCTs), and pedagogy and leadership training, conducted by VSOs. Thus, a total of 207 participants were involved in this study, including 8 college principals, 181 tutors, 8 district teacher trainers and 10 material developers. Whereas purposeful sampling technique was used to select principals and members of the national trainer training (Baseline) team, random sampling technique was used to select college staff who participated in English language and pedagogy and leadership training. Table 2 shows the distribution of the participants in the study by College. 
Mkonongwa, L. M., \& Komba, S. C.

Table 2

Distribution of participants by college

\begin{tabular}{|c|c|c|c|c|}
\hline College & $\begin{array}{c}\text { Number of } \\
\text { principals }\end{array}$ & Tutors & $\begin{array}{l}\text { Trainer training } \\
\text { team (Baseline) }\end{array}$ & Material developers \\
\hline Butimba & 1 & 24 & 1 & - \\
\hline Patandi & 1 & 24 & - & - \\
\hline Katoke & 1 & 17 & 2 & 3 \\
\hline Vikindu & 1 & 14 & 1 & 1 \\
\hline Kleruu & 1 & 21 & - & - \\
\hline Marangu & 1 & 30 & - & 2 \\
\hline Morogoro & 1 & 28 & 2 & 3 \\
\hline Mpuguso & 1 & 23 & 2 & 1 \\
\hline Total & 8 & 181 & 8 & 10 \\
\hline
\end{tabular}

Two kinds of data were collected: secondary and primary data. Secondary data were collected through desk review which provided information on the activities that had already been completed by the project. The primary data provided a detailed field experience of the project implementation and its impact to the beneficiaries. The data were collected in four main ways, including document review, structured survey, interviews and focus group discussions. The research team reviewed literature and documents such as EQUIPT quarterly reports prepared by the British Council and the Baseline materials used for the teacher training. Self-completion questionnaire was used to collect information on tutors' perceptions of the two interventions that were implemented in their colleges. A semi-structured interview was used to collect data from principals and tutors. The interviews were intended to gather detailed information on the professional development changes individual tutors and colleges as institutions had undergone as a result of the interventions as well as the 'cross-over' of skills from the Baseline core team to their college departments. The interviews also helped the researchers to ascertain the impact of the college-based intervention model, the complementarities of the two interventions and the perceived relationship between Year 1 and Year 2 of the interventions. Focus group discussions were used to compliment data collected through questionnaires and interviews with a view of triangulating the information collected by the two instruments.

With regard to ethical considerations, participants were informed about the purpose of the study and they were requested to sign a consent form to show their willingness to participate in the study. In addition, the participants were told to be free to quit at any stage during data collection in case they felt uncomfortable to continue participating.

Data analysis was done in line with the study objectives. The objectives were translated into themes which formed the basis of data analysis, presentation and discussions. Quantitative data were analyzed using the SPSS software while ATLAS.ti. 6.2 programme was used to analyze qualitative data. Codes for analysis of qualitative data were developed on the basis of the main themes of the study and were used to sort the potential issues that emerged from interview and focus group discussions. Similar responses made by different respondents were counted and converted into percentage and frequencies presented in the form of figures and charts.

\section{Findings and discussion}

\subsection{Effects of providing two complementary interventions in Phase 1}

The first objective of this study sought to examine the effects of providing two complementary interventions (BC and VSO) in Phase 1. Specifically, this section answers this question: What were the effects of providing two complementary interventions in Phase 1? The findings from this study revealed that there were both positive and negative effects of providing two complementary interventions as follows: 
Enhancing teaching and learning through improved English language teaching and educational management

Positive effects - The positive effects of providing two complementary interventions as pointed out by the participants can be described in terms of three main areas which include teaching methodology (pedagogy), coaching and mentoring, and transferability of knowledge and skills.

With regard to teaching methodology, it was revealed that, although the two teams worked autonomously to a larger extent, both the BC and VSO facilitators offered lessons on teaching methodology and thus, tutors had a better chance of acquiring pedagogical skills from both teams. For instance, in all colleges, participants reported that they were able to use participatory teaching methods which were emphasized by both the BC and VSO facilitators during the training. This is evident from the words of one of the participants who stated: "The training helped me to understand how to use participatory teaching methods which I did not know how to use them before" (T. 19). In the same light, another participant admitted to have learnt how to use gallery walk, simulations and songs in teaching various subjects. This is clear from his words:

My teaching methodology has improved to a great extent. For instance, I learned how to use gallery walk, simulations and translated English songs to Kiswahili language in teaching. I did not know this before (T. 04).

From these findings, it is evident that the majority of participants had gained adequate knowledge and skills on the use of various teaching methods, hence increasing their confidence and effectiveness in teaching. In addition, the participants were able to select and use appropriate teaching methods depending on their subject matter and context, handle large classes and use appropriate language. This is justified by one of the tutors at Mpuguso TC who made this remark:

Yes, the materials considered the number of students we are having in our classroom. I also learned about appropriate language use when teaching, class seating arrangement, class participation, and relationship with students. I learned to be a friend to students. I learned that pupils can be very good if you are friendly in the language you use, the activities you provide them, the songs, and games. I am luck that I was involved in the project (T. 14).

This is similar to the observation made by another participant that:

The training has helped me to learn and improve my ability to use different teaching methods and techniques. I have used them in my classrooms and I have realized that they work very well (T. 09).

It was also revealed from the two interventions that tutors not only gained pedagogical skills but also improved their academic competences and the certificates they received from the training enabled them to apply for new jobs. This is justified by the remarks made by one of the tutors at Butimba Teachers' College:

I was satisfied with the training because it touched areas of my interest and it was offered for free. The training helped me to improve academically and in my teaching methodology. Also, the training provided us with certificates which I can use to apply for other employment and/or study opportunities. For instance, I used the certificate I received from the training to apply for a job and I got it. The only challenge is that the time for training was very short. In future, I suggest the training to be offered for a relatively longer time (T. 11).

The transfer of knowledge and skills was reported by many participants as one of the major effects of providing two complementary interventions. The transferability of knowledge and skills reported by the participants was mainly in terms of the preparation of lessons, designing teaching aids and development of the spirit of teamwork. The findings of this study revealed that the majority of participants gained knowledge on preparing lessons and designing teaching aids by using locally available materials. For instance, the BCs introduced the idea of 'concept checking' as key to the lesson development while the VSOs trained tutors how to prepare teaching aids by using materials available in their own surroundings. In this way, tutors gained double 
Mkonongwa, L. M., \& Komba, S. C.

skills as a result of the two interventions running at the same time. This can be noted from the comment of one the participants:

......We were so privileged to have VSO from different countries that were very cooperative.....The

VSOs collaborated with tutors in the activities of preparing teaching aids (T.21).

Similarly, another participant narrated how the skills of preparing teaching aids helped her to teach English language lessons. This is what she said: "On my side, the training helped me because I learned how to teach phonology topic by using teaching aids". This shows how the knowledge gained from the VSOs was applied in the $\mathrm{BC}$ lessons.

Moreover, it was reported by the participants that the teamwork spirit which was developed through group assignments during the training in both interventions was eventually adopted in the day to day undertakings in the colleges. For instance, in some colleges such as Butimba, it was reported that after the training, the college administration formed groups of tutors to perform certain tasks such as developing project write-ups and establishing new units, clubs and platforms. For example, Butimba TC established Butimba Education Forum (BEF) which, among other things, is concerned with preparations of academic competitions, such as essay writing competitions. In performing all these activities, tutors employed skills gained from both interventions.

Regarding mentoring, coaching and leadership skills, the findings indicated that the provision of the two complementary interventions had an impact on the tutors in terms of development of mentoring, coaching and leadership skills. The tutors reported that they were not only trained in English language, pedagogy and leadership but also mentored and coached on developing strategic plans, project proposals, and writing appropriate vision and mission statements for their colleges. In order to do all these activities, tutors applied both language skills and managerial skills.

Moreover, it was reported that tutors who were on studies were supported by both BC and VSO trainers by having their proposals and research reports proofread. This is evident from a story narrated by one of the principals as follows:

The trainers on the side of leadership (VSOs) started by holding meetings in the departments and later they organized a workshop for all. There were sessions where tutors had opportunity to present their research works. The English language trainer helped some tutors who were enrolled at St. Augustine University to proofread their master's thesis (P. 04).

Despite the fact that each intervention was implemented as an independent activity, the knowledge and skills obtained from the two interventions positively influenced each other. This is due to the reason that the participants were able to combine the English language and pedagogical knowledge and skills acquired from both interventions in not only teaching but also their day to day activities. To show this link, one of the tutors had this to state:

The training was not so bad, because I learned different components which they wanted us to learn; to construct sentences, the structure, how to develop verbal ability, and skills of interaction with learners. The training was enhancing pedagogical skills of a tutor on how to take a learner to understand a lesson (T.02).

Therefore, it could be concluded that there were tremendous knowledge, skills and experiences which tutors gained from the two interventions, which can be applied independently and in combination in their day to day teaching and career development.

Negative effects - The negative effects of providing two complementary interventions can be described from three main perspectives. These include inconsistencies in service provision, lack of proper communication and timing. 
In terms of consistency, the findings of this study indicated that there were inconsistencies in the services provided to tutors during the training. Many participants reported that the VSO provided breakfast and lunch during their workshops while the BC trainers did not offer such services. Such differences in the treatment of participants in the two interventions led to unnecessary complaints against the $\mathrm{BC}$ trainers, affecting the participants' attendance and participation in the BC sessions.

It was also revealed that different colleges had different modalities for organizing activities of the two interventions. Whereas in some colleges all tutors participated in the activities of BCs and VSOs, in other college tutors were split into two groups: those who worked with BCs and those who worked with VSOs. In addition, there were other projects running within the colleges, such as the project which focused on improving reading, writing and arithmetic, popularly known as "KKK" (i.e. kusoma, kuandika na kuhesabu) in Kiswahili. The multiplicity of projects brought confusion on the part of the tutors as explained by one of the participants who had this to report: "...this was so confusing to tutors who were expected to implement multiple tasks. I think the Ministry did not think critically about the effectiveness of this entire project” (T. 13).

In addition, the variations in the modalities of implementing the two interventions within the colleges indicated that there were tutors who benefited from both interventions and those who benefited from only one of the interventions.

Lack of proper communication was indicated as another negative effect of the implementation of two complementary interventions. During the study, the participants reported that there were changes in policy which the government introduced. Such changes in one way or another affected the implementation of the two interventions. For instance, the introduction of Kiswahili as a language of instruction in all teacher training colleges affected the English for Teaching programme offered by the BC. As a result, some tutors started to undermine the English language training for the reason that they would have nowhere to use the skills because they were going to teach in Kiswahili. Therefore, they paid more attention to the pedagogical and leadership sessions offered by VSOs which they considered still useful. One tutor stated:

To be frank, I cannot apply the knowledge I acquired from the training due to the change of language of instruction in teachers' colleges. Formerly, we were using English as a medium of instruction but recently the government has changed the language of instruction from English to Swahili. For this reason, tutors feel that they wasted their time learning the language they cannot use in teaching (P. 01).

Following these changes, the BC shifted the attention from English language training in teachers' colleges to improving English language in secondary schools through the use of Baseline materials. Some tutors from teachers' colleges were designated to a core team who trained District Teacher Trainers (DTTs) to train secondary school teachers on the use of the Baseline materials for Form One students. Therefore, if there was proper communication or dialogue between the MoEVT and the British Council, there would not be such interruptions. If there had been more open dialogue, project planning would have improved and the project resources (human, financial) would have been used more effectively.

Another change which affected the English language training intervention was the transfer of teachers' colleges from being a department controlled by the Directorate of Teacher Education within the Ministry of education to autonomous institutions regulated by the National Council for Technical Education (NACTE). This transformation went hand in hand with the introduction of new programmes in teacher education such as diploma in early childhood education which among other things emphasised the three "Rs", that is, reading, writing and arithmetic, translated as triple "KKK"- kusoma, kuandika na kuhesabu in Kiswahili. The British Council was not aware of these new plans and there were no BC facilitators prepared to train tutors to deliver English as a subject in these new programmes.

Therefore, it can be concluded that the changes introduced by the Ministry affected the English language 
intervention in teachers' colleges, to some extent. The decision of the $\mathrm{BC}$ to turn attention to the Baseline for secondary schools led to the two interventions operating in two separate settings hence weakening their integration and the possibility of complementing each other.

\subsection{Short and long-term effects of using a college-based intervention model}

The other objective of this study was to ascertain if there were any short-term and long-term effects of using a college-based intervention model. The findings indicated that the college-based intervention model was perceived to have both positive and negative effects. In terms of positive effects, the respondents pointed out that the model was cost-efficient and that the knowledge acquired was applied immediately in real situations. This was also evident from the responses provided by respondents in the questionnaire, where the majority indicated readiness to recommend the project to continue in subsequent years.

However, the main negative effect which was indicated by the respondents concerned the timetable interference between the training schedule and normal college timetable. It is worth noting that the training intervention went hand in hand with other college activities. In view of this, some tutors especially those with administrative duties, were unable to attend the training consistently. As a result, they missed a number of sessions which eventually led to the acquisition of fewer skills.

It was further revealed that Diploma Teachers' Colleges were more affected by timetable interference than Certificate Teachers' Colleges. As such, some of the respondents suggested the training to be conducted during vacation or in the evening after normal working hours.

Apart from short-term effects, there were long-term effects of the college-based model as well, which were highlighted by the respondents. During interviews, some tutors revealed that through workshops, they learnt how to review and develop proper vision and mission statements for their colleges. They also learnt how to develop strategic plans and project proposals. Consequently, tutors who participated fully in such activities seemed to be potential human resource for the respective colleges.

Moreover, the VSOs and BCs mentored the tutors on issues related to time management and record keeping. Furthermore, through college-based model, the VSOs and BCs helped the colleges to establish new units and clubs such as in-service training units, research and publication units, and subject clubs. Additionally, the presence of the BCs in the colleges led to increased use of English language in different college events such as meetings and parades which consequently contributed to improved English language proficiency among tutors.

\subsection{Professional development changes at institutional level}

In connection with professional development changes at institutional level, the respondents were asked to explain the professional development changes the colleges had undergone as a result of the interventions. The respondents pointed out that the main changes included improved human resource capacity in terms of development of new teaching and leadership skills, improved English language proficiency among staff and enhanced teamwork spirit. This is evident from the words of one of the tutors as follows:

...As a college we have benefited a lot from the project. First, the training has made the college to have staff with high ability to perform various duties such as teaching, developing policies, etc. Secondly, the training has enabled us as college administrators to work better especially at this time when we are working under National Council for Technical Education (NACTE). NACTE wants us to develop our mission, vision and strategic plans. The skills we acquired from this training are very useful in accomplishing all these (T. 10).

It was also reported that colleges benefited from teaching materials (books) as well as teaching aids and artifacts developed during the project. It was evident from the respondents that before the introduction of the project, tutors had less leadership skills as well as skills for using locally available materials to design teaching 
Enhancing teaching and learning through improved English language teaching and educational management

aids. In addition, very often, teachers had to wait for industrial made teaching aids, particularly in science subjects while ignoring the possibilities of working with their students in designing teaching aids through improvisation.

Moreover, one of the College Principals commented that the project contributed to the improvement in performance of students in English language examinations. Stressing on this matter, the Principal had this to state:

The direct benefit that we got as a college is that there was an abrupt improvement of our students' performance in English language examination results. In 2014 ... (calls the secretary to bring the file that shows the results). Before 2014 many college students were failing English language examination. The training started in 2013 May if I am not mistake, in fact were surprised, as a result of English language Department efforts and the techniques that the facilitator taught us, then, our college students performed very well. Few students failed as compared to the previous year's performance. I think when the file comes, you will see the performance (P. 03).

Furthermore, the respondents indicated that in some colleges, apart from working with tutors, the trainers (VSOs and BCs) were also directly involved in training student teachers. This brought a significant impact on the professional development of student teachers.

Also, the trainers were reported to influence the establishment of some programmes in the teachers' colleges which did not exist before the project. These include the introduction of new sports and games and education forums.

Nevertheless, it is important to note that the success and benefits which individual colleges experienced depended on the attitude of the college top management, especially the Principal. The study has revealed that in colleges where the Principal was serious and had positive attitude towards the project, there was high participation of the tutors in the training. For instance, in some colleges, it was compulsory for all tutors to attend the training and strict follow-up mechanisms were put in place to ensure effective participation. This is justified by the response of one of the tutors when he was asked whether he participated in the training voluntarily or by force. This was his response:

To a certain extent, the training had some elements of force because every tutor was compelled to submit his/her timetable to the office of the College principal in order to determine the dates when each tutor will attend the training. However, there was no punishment for tutors who did not attend (P. 02).

The situation was different in colleges where the college management either had negative attitude or lacked seriousness in supervising the activities of the project. Tutors in such colleges had great freedom to choose either to participate or refrain from the project activities. The study revealed that in some colleges the tutors participated fully and worked hard in the assignments given during the training because of the individual efforts of the facilitators to encourage the tutors and close supervision. For instance, the facilitators had attendance sheets in which tutors had to sign after every training session and followed up to make sure that each tutor accomplished the assignments given during the training. Therefore, some tutors worked hard because they feared to be ashamed for not completing their tasks. This is evident from the words of one tutor who had this to report:

There were so many trainers, and their procedures were a bit unique to us because they discussed with us issues related to leadership and job performance procedures. They gave us assignments to do on our own. After a short while they did follow up to check the implementation of the provided task. This made us work hard on the tasks provided because we knew that when we meet them during the next session they would ask about the task progress (T. 21). 
Mkonongwa, L. M., \& Komba, S. C.

In view of these findings, it could be noted that in the course of implementing any project in the colleges or schools, the heads of such institutions need to be highly involved in the planning process because of their great influence on either success or failure of the project. Therefore, at the planning stage of any project, it is important to involve the heads of the implementing institutions so as to establish common goals and understanding of the project for the smooth implementation of the same.

\subsection{Professional development changes for individual tutors}

With regard to professional development changes for individual tutors, the findings indicated that there were diverse views among tutors. While a small number of tutors felt that the project had little impact on their personal professional development, a large number of them acknowledged that the project had great contribution to their professional development.

The tutors who believed that the project had minimal contribution to their professional development gave the reason that there was no opportunity for tutors to be observed in their classrooms after the training in order to ascertain the extent to which they applied the learned skills. In connection with this, some tutors believed that the project was more relevant to tutors of English language subject than those of other subjects. This implies that there was a misinterpretation of the project by some tutors. Such misinterpretation could be attributed to the reason that some tutors were misinformed about the purpose and relevance of the project since tutors who were well informed about the project participated actively in the training sessions and other project activities. One of the college tutors had this to report:

I willingly participated in the training but some of us were not motivated because they felt that the project was not relevant to them. They perceived the training as more appropriate for English language teachers than other teachers such as those teaching science subjects. On my side, I attended all training sessions and I am able to apply extensively the knowledge and skills acquired from the training. The most important thing to consider, however, is for the teachers to select and use the materials and methodologies in accordance with their subjects of specialization (T. 16).

Respondents who appreciated that the project had positive contributions on their professional development reported changes such as improvement in English language proficiency and pedagogical and leadership skills; increased time management skills and enhanced teaching confidence. Each of these professional development changes are further analyzed below.

\subsection{The perceived relationship between the Year 1 and Year 2 interventions}

The respondents were also asked to indicate their perceptions of the relationship between Year 1 and Year 2 interventions. On this aspect, the respondents had different perceptions as some reported that there was a relationship between year 1 and year 2 of the interventions while others argued that there was a missing connection between the two years of interventions. One of those who reported that there was a link pointed out that:

There was a close connection between phase one (training) and phase two (material development). The knowledge obtained from the training was used in the material development, in phase two (T. 08).

Another respondent had this to comment:

I feel that there was connection between the two phases although the materials were too many to cover them all within the available time. I suggest the materials be summarized (T. 12).

On the other side, one of the respondents who stated that there was no connection between the activities in 
year 1 and year 2 of the intervention had this to report:

In my view, there was a missing connection between the two phases because after the training, the materials provided to teachers were not used due to the change of the language of instruction from English to Kiswahili. Many tutors found themselves shelving the materials without using them (T. 09).

On the same light, another respondent from a Diploma college added:

In my opinion, there was no connection between the two phases because in phase one tutors attended the training but in the second phase tutors were given English teaching materials which were not applied. Also, there were no guidelines on when and how the materials were to be applied (T. 04).

The variations in responses indicate divergent views of the participants with regard to the relationship between the two phases. This could be attributed to the role each participant played in the project during the two years and the transfer of TCs from the control of the Ministry of Education Science and Technology to that of National Council for Technical Education (NACTE). According to NACTE regulations, teaching in all TCs has to be done in Swahili and English language remains as a subject.

\subsection{Crossover of skills from the baseline core team to the college departments}

The other objective in this study was to examine whether there was any cross over skills from the baseline core team to the college departments. Specifically the researchers were interested to find out whether the members of the Baseline core team were able to use and share the knowledge and skills acquired from the training with the other tutors in their respective departments. The respondents had different responses as some reported that there was a crossover effect of the skills from the Baseline team to their departments while others stated that there was none.

The differences in responses could be attributed to the fact that tutors who were involved in the Baseline core team came from a few departments. Such members were more likely to share the knowledge and skills with members from within their departments rather than those from other departments in the respective colleges.

\section{Conclusions and Recommendations}

This study has revealed that the EQUIPT ELT project has a significant impact on the improvement of the quality of teaching and management of teachers' colleges in Tanzania. Since English will continue being the medium of instruction in secondary schools, the Baseline materials developed during the project implementation will continue to be useful for orientation to Form One students. Therefore, the Baseline materials need to be distributed to all secondary schools in the country.

Although the language of instruction for ordinary diploma programme for primary is Kiswahili, the importance of training tutors in English language should not be underrated. There is a likelihood for some teacher trainees graduating from these colleges being posted to teach in secondary schools where English is the language of instruction. Thus, they require a high level of English language proficiency in order to teach competently and confidently. Moreover, as teacher training colleges are becoming autonomous, they will require highly qualified staff to initiate new and more advanced academic programmes as well as more knowledgeable and highly skilled individuals to hold administrative posts. In order to achieve this, colleges will be compelled to initiate professional development programmes for their staff which in any case will be conducted in English language. Therefore, English language competence for tutors is mandatory for their professional development and sustainability of their institutions.

Based on the findings of this study, the following recommendations are made: First, the college-based 
Mkonongwa, L. M., \& Komba, S. C.

intervention model has proved to be effective and cost-efficient. Therefore, the Ministry of Education Science and Technology and project partners should embrace the in-service training model in the future to ensure project effectiveness and value for money. Secondly, the duration for training, particularly on pedagogy and leadership skills, was too short to accommodate all aspects of the training. Therefore, in future, the training intervention should be organized during vacation to avoid the programme interfering with college routines. Third, the Ministry of Education, Science and Technology, through the college principals, should educate tutors to have their attitudes changed so that they should not expect financial incentives during training. They should rather count on value of knowledge and skills they acquire from the training. Lastly, the Ministry should encourage the colleges to make use of the tutors who had their knowledge and skills developed through their involvement in the Baseline activities (Baseline core team) to share their knowledge and skills with their colleagues through peer teaching and coaching.

\section{References}

Brock-Utne, B., \& Desai, Z. (2010). Expressing oneself through writing - A comparative study of learners' writing skills in Tanzania and South Africa. In B. Brock-Utne, Z. Desai, \& M. A. S. Qorro (Eds.), Language of instruction in Tanzania and South Africa - Highlights from a project (pp. 11-32). Rotterdam: Sense Publishers.

Galabawa, J. C. J., \& Senkoro, F. (2010). Implications of changing the language of instruction in secondary and tertiary education in Tanzania. In B. Brock-Utne, Z. Desai, M. A.S. Qorro \& A. Pitman (Eds.). Language of instruction in Tanzania and South Africa - Highlights from a project (pp. 145-156). Rotterdam: Sense Publishers.

Komba, S. C., \& Bosco, S. (2015). Do students' backgrounds in the language of instruction influence secondary school academic performance? Journal of Education and Practice, 6(30), 148-156.

Makewa, L.N., Role, E., \& Tuguta, E. (2013). Students' perceived level of English proficiency in secondary Schools in Dodoma, Tanzania. International Journal of instruction, 6(2), 35-52.

Mosha, M. A. ( 2014). Factors affecting students' performance in English language in Zanzibar rural and urban secondary schools. Journal of Education and Practice, 5(35), 64-76.

Murasi, M. G. (2013). The role of the baseline orientation course in enhancing learners' transition from primary to secondary education in Tanzania: The case of Dodoma municipality (Unpublished Master's thesis). The University of Dodoma.

Mwinsheikhe, H. M. (2003). Overcoming the language barrier: An in-depth study of the Tanzania secondary school science teachers' initiatives in coping with the English-Kiswahili dilemma in the teaching-learning process (Unpublished Doctoral thesis). University of Oslo.

Sumra, S., \& Rajani, R. (2006). Secondary education in Tanzania: Key policy challenges. Working Paper No.4. Hakielimu.

Tshabangu, I., \& Msafiri, A. (2013). Quality education in Tanzania: Perceptions on global challenges and local needs. International Journal of Asian Social Science, 3(3), 800-813.

United Republic of Tanzania. (2010). Public expenditure tracking survey of primary and secondary education: Final Report. Dar es Salaam: Ministry of Education and Vocational Training.

United Republic of Tanzania. (2014). Pre-Primary, primary and secondary education statistics 2013: Regional data. Dodoma: Prime Minister's Office, Regional Administration and Local Government, Tanzania. 